\title{
Clinical Events Completion Status
}

National Cancer Institute

\section{Source}

National Cancer Institute. Clinical Events Completion Status. NCI Thesaurus. Code

C113354.

A term used to describe the state or condition of the completeness of the clinical events data. 